\title{
Interconversion of Electronic Spin State of $p$-Substituted Arylketocarbene Reactions
}

\author{
Dae Dong Sung, ${ }^{\star}$ Jin Hee Jeong, Zoon Ha Ryu, ${ }^{+}$Won Bae Chin, ${ }^{\star}$ and Ikchoon Lee \\ Department of Chemistry. Dong-A University; Busan 604-714, Korea \\ "Deparment of Chemistry, Dong-Eui University: Busan 614-714, Korea \\ ${ }^{\ddagger}$ Department of Physics, Dong-A University, Busam 60-4-7/4. Korea

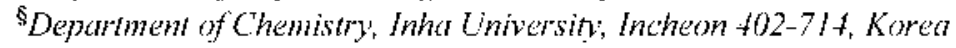 \\ Received February 17, 2004
}

\begin{abstract}
Rate constants for photolytic reactions of $p$-substituted 2-diazopropiophenones were deternined in acetonitrile. The reactions show a comparatively low value of activation energy and activation enthalpy to alkylcarbenes or other arylcarbenes. The transition state corresponds to the step of a new carbonyl bond formation. The high negative $\rho$-values are shown in Hammett plots. The kinetics results and EPR spectrum are in accord with a phenomenon that occurs in interconversion between singlet and triplet carbenes.
\end{abstract}

Key Words : Arylketocarbenes, Singlet-triplet interconversion, Photolytic rate constant

\section{Introduction}

Arylketocarbenes are of interest in the field of reactive carbene intermediates including the Wolff rearrangement reactions. ${ }^{1-6}$ Among many arylketocarbenes several benzoylcarbenes have been characterized by matrix Г.PR spectroscopy. ${ }^{7}$ Benzoylphenylcarbene (singlet phenyketocarbene: SPKC), I could be generated by photolysis $(\lambda \geq 345 \mathrm{~nm})$ of azibenzil in organic glasses of 2-methyltetrahydrofuran or in powder at $77 \mathrm{~K}^{8-10}$

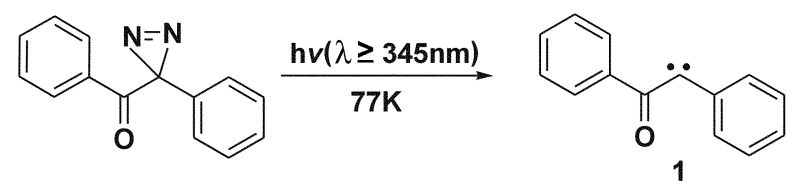

The EPR spectra of benzoylphenylcarbene ${ }^{8-10}$ give a good proof related to ketene intemediate, 4 and intersystem crossing (ISC) to the singlet carbenc, 3 with subsequent Wolff rearrangement.

Another application of the arylketocarbene, one of benzyloxycarbenes, Muorophenoxycarbene, 6 is generated by the themolysis of 3-fluoro-3-phenoxydiazirine, 5 and reacts with a series of alkenes to produce the corresponding cyclopropanes. ${ }^{11}$

Generally, alkylcarbenes give ylide intermediates, 7 in their trapping compounds as acetonitrile or pyridine. ${ }^{12-17}$

Nlthough many alkylketocarbene reactions with acetonitrile or pyridine quenchers have been studied, the ylide intermediates involving arylketocarbene with acetonitrile or pyridine have nol yet reported.

The thermolysis or photolysis of benzyloxylluorodiazi-

Scheme 1<smiles>C=C(C(=O)c1ccccc1)C(=CC)CC</smiles>

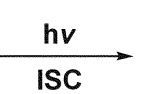

2

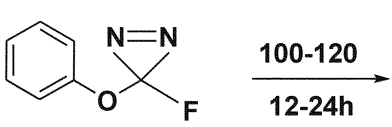<smiles>O=C(Nc1ccccc1)c1ccccc1</smiles>

3<smiles>O=C=C(c1ccccc1)c1ccccc1</smiles>

4

Scheme 2
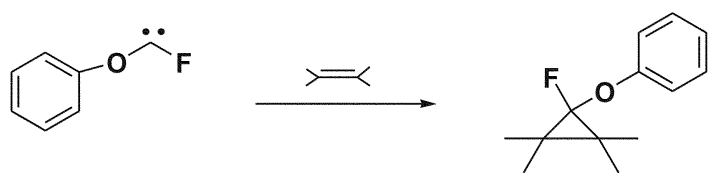

6

$$
\stackrel{\mathbf{R}^{\prime}}{\mathbf{R}}: \quad \frac{\mathrm{hv}}{\mathrm{CH}_{3} \mathrm{CN} \text { or Pyridine }}
$$<smiles>[R]C([R])[N+]#CC</smiles>

or<smiles>[R]C([R])[n+]1ccccc1</smiles> 


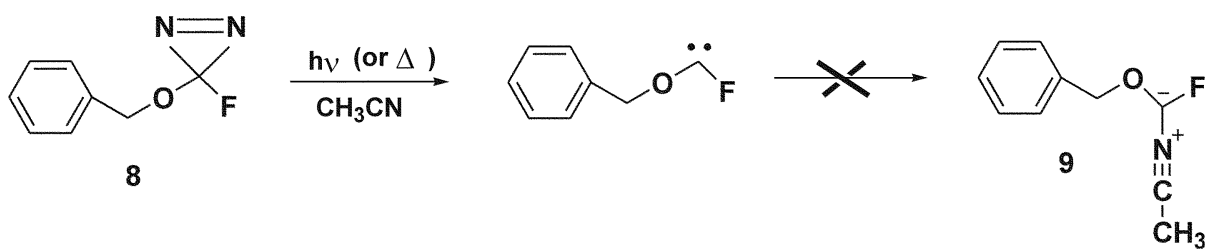

Scheme 5
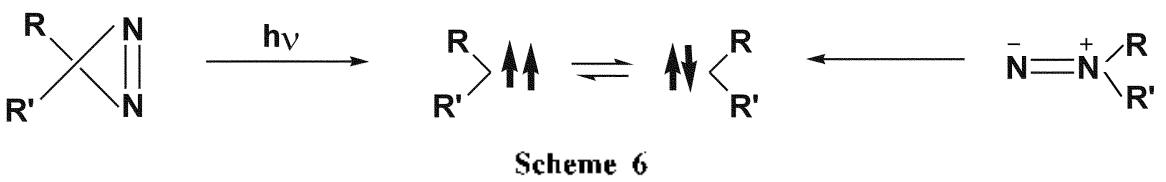

rine, 8 does not produce ylide intermediate $9 .^{\text {'I }}$

The behavior of alkylcarbomethoxycarbene has been reported that is completely different behavior from arylcarbomethoxy carbene. ${ }^{\left.8-l^{4}\right)}$

Generally it is well known that photolysis of alkyl carbomethoxy carbene gives a product of triplet sensitization. Triplet sensitization lowers the yield of the product abstracted from singlet carbene as well as the yield of the product of $\mathrm{C}-\mathrm{H}$ insertion. The $\mathrm{C}-\mathrm{H}$ insertion product gives a different result as shown a singlet carbene origin, in contrast to the behavior of phenyl carbene and diphenyl carbene. However it is difficult to find a mechanistic approach for electronic state of arylketocarbene.

It is important to identify and understand the true electronic spin state of arylketocarbenes produced from arylketodiazo compounds. However, most arylketocarbenes were characterized soon after generation from azibenzyl derivatives, ${ }^{20-22}$

Therefore it is necessary to identify a clear-cut photolytic experimental results. Most cases ${ }^{1+15.23 .2 .1}$ show there are different electronic spin-state in accordance with producing from diazirine derivatives or diazo derivatives as shown in Scheme 6.

A question arises whether the electronic spin state of arylketocarbene changes from singlet origin to triplet within a small energy gap, or prohibit the intersystem crossing along with alternation of the substituents on the phenyl ring. We report here a more detailed reaction mechanism of $p$ substituted phenylketocarbenes based on reactivity involving a singlet-triplet interconversion.

\section{Experimental Section}

Materials. $p$-Substituted phenyl- $\alpha$-diazo ketones ( $p$ substituted 2-diazopro-piophenones) were synthesized freshly by the literature procedure ${ }^{25}$ A $100 \mathrm{~mL}$, three-neck. round-bottom flask, wrapped with aluminum foil and equipped with a Dean-Stark trap, stir bar, and argon inlet was placed in ice-bath controlled to $0{ }^{\circ} \mathrm{C}$ and then was charged with $N$-nitroso- $N$-ethyl urea $(0.86 \mathrm{~g}, 7.34 \mathrm{mmol})$ and $40 \mathrm{~mL}$ of diethyl ether and purged with nitrogen for 20 min. To this were added aqueous $\mathrm{KOH}$ solution $(10 \mathrm{~mL}$ of $40 \%$ solution). The mixture was stirred at $0{ }^{\circ} \mathrm{C}$ for $30 \mathrm{~min}$.
The reaction mixture was warmed to room temperature and the organic layer was separated from water layer. Sodium hydroxide (2 g) was added into the organic layer and was stirred for $5 \mathrm{~min}$, at $0^{\circ} \mathrm{C}$. Diethyl ether $(10 \mathrm{~mL}$ ) and 0.85 minol of $p$-substituted benzoyl chloride were added and stirred continuously at $0^{\circ} \mathrm{C}$ for $20 \mathrm{hr}$. The organic layer was washed with petroleum ether and dried. The solvent was removed in vacuo to give $0.60 \mathrm{mmol}$ of impure 2diazopropiophenone of a viscous yellowish red oil, which was purified by medium pressure licjuid chromatography using bexane/ethyl acetate $(2: 1)$ as the eluent to afford 0.52 mmol of pure 2-diazopropiophenone :

p-Methoxy-2-diazopropiophenone ( $p-\mathrm{OCH}_{3}$ ): IR (KBr) $2972,2867,2360,2070,1601,1508,1343,1230,1157$. $1002,839,565 \mathrm{~cm}^{-1}:$ 'H NMR $\left(\mathrm{CDCl}_{3}\right) \delta 2.56(\mathrm{~s}, 3 \mathrm{H}), 3.88$ $(\mathrm{s}, 3 \mathrm{H}), 6.93(\mathrm{~m}, 2 \mathrm{H}), 7.94(\mathrm{~m}, 2 \mathrm{H})$.

p-Methyl-2-diazopropiophenone (p-CH3): IR (KBr) $2975,2864,2362,2068,1748,1599,1341,1230,1001.884$ $\mathrm{cm}^{-1} ;{ }^{1} \mathrm{H} \mathrm{NMR}\left(\mathrm{CDCl}_{3}\right) \delta 2.40(\mathrm{~s}, 3 \mathrm{H}), 2.59(\mathrm{~s}, 3 \mathrm{H}), 7.25(\mathrm{~m}$. $2 \mathrm{H}) .7 .86(\mathrm{~m}, 2 \mathrm{H})$.

2-Diazopropiophenone (p-H): IR (KBr) 2977, 2863, $2362,2073,1509,1507,1341,1187,982,567 \mathrm{~cm}^{-1}:{ }^{1} \mathrm{H}$ NMR $\left(\mathrm{CDCl}_{3}\right) \delta 2.61(\mathrm{~s}, 3 \mathrm{H}), 7.48(\mathrm{~m}, 2 \mathrm{H}), 7.55(\mathrm{~m}, 1 \mathrm{H})$, $7.98(\mathrm{~m}, 2 \mathrm{H})$.

p-Fluoro-2-diazopropiophenone ( $p$-F): $\mathrm{IR}$ ( $\mathrm{KBr}$ ) 2977 , $2869,2362,2070,1781,1749,1607,1507,1343,638 \mathrm{~cm}^{-1}$; ${ }^{1} \mathrm{H}$ NMR $(\mathrm{CDCl}) \delta 2.66(\mathrm{~s}, 3 \mathrm{H}), 6.89(\mathrm{~m}, 2 \mathrm{H}), 7.26(\mathrm{~m}, 2 \mathrm{H})$.

Apparatus and Characterization. The synthesized samples were characterized before using. F"l-IR spectra were recorded on a Bruker IFS 55 spectrophotometer. 'H NMR spectra were measured on a Bruker AC-200 Fl, $200 \mathrm{MHz}$ spectrometer and are reported in parts per million downfield from tetramethylsilane. Gas Chromatograph/Mass Spectrometer (GC/MS) analysis was accomplished using a HewlettPackard 5890 AX 505 WA with a flame ionization detector and a $30 \mathrm{~m} \times 0.254 \mathrm{~mm}$ ID. DB-1 column. The oven temperature was controlled with the retained time as follows: $70^{\circ} \mathrm{C}$ (2 min.) to $180^{\circ} \mathrm{C}$ at $10^{\circ} \mathrm{C} / \mathrm{min}$., hold $2 \mathrm{~min}$. to $225^{\circ} \mathrm{C}$ at $30^{\circ} \mathrm{C} / \mathrm{min}$. hold $5 \mathrm{~min}$. Products of the photolysis mixture were isolated by use of either a preparatory thin layer chromatograph or a high performance liquid chromatograph (HPLC). In product isolation the reaction mixtures were concentrated by pumping off most of 
the solvent prior to application to the thin layer chromatograph plates. A nitrogen-filled vacuum atmosphere dry box equipped with a dri-train gas purifier was employed for manipulations when the reaction was carried out under anaerobic conditions.

Kinetics. Photochemical kinetics were monitored using a Shimadzu UV/Vis-240 spectrophotometer equipped with the Cary sixcell Peltier constant temperature accessory as previously reported. ${ }^{26-28}$ A stock solution of $p$-substituted 2diazo-propiophenone in diethyl ether was injected into a equilibrated acetonitrile for $30 \mathrm{~min}$. and the change in absorbance was followed at $248,251,253$ and $254 \mathrm{~nm}$ for compounds $p-\mathrm{OCH}_{3}, p-\mathrm{CH}_{3}, p-\mathrm{H}, p$ - $\mathrm{F}$, respectively. Firstorder rate constants for photochemical reactions were determined by a nonlinear least-squares fit to a standard first-order equation. All kinetic runs exhibited exactly firstorder behavior for at least 3 half-lives of reaction.

Low Temperature EPR Spectroscopy. F.PR measurements were made with a Bruker ESP 300E: X-band spectrometer as previously reported ${ }^{27}$ and g-values were calibrated with 2,2-diphenyl-1-picrylhydrazyl using Bruker .RO35M NMR gaussmeter. The sample of $p-\mathrm{H}$ was $0.30 \mathrm{ml}$. and were contained in 3- $\mathrm{mm}$ cylindrical Suprasil quartz. F.PR tubes. The samples were sealed under vacuum after three freezethaw cycles to remove traces of oxygen and photolyzed for 3-5 min, using 300 or $350 \mathrm{~nm}$ lamps. The sample was stored in liquid nitrogen between measurements. The spectrum was obtained at $0.2 \mathrm{G}$ modulation amplitude, a modulation frequency of $100 \mathrm{kH}_{7}$, and an incident microwave power of $8 \mathrm{~mW}$. The field-frequency lock accessory was operated automatically programmed with automatic frequency control modulation amplitude correction over the attenuation range. Spin concentration measurements were carried out on a dual $\mathrm{TF}_{111}$ rectangular cavity. 2-Diazopropiophenone was cooled to $77 \mathrm{~K}$ in cryogenics (CTI, Helium $99.999 \%$ Closed System, R.G.Hansen \& Associates l.aboratory Cryogenics Systems, Model No. 2561) and photolyzed with $350 \mathrm{~mm}$ radiation from a Rayonet Reactor. ГPR signals are observed at 2200 . 5100 and $6200 \mathrm{G}$. The triplet EPR spectrum was assigned to yield zero field splitting ( $\angle F S$ ) parameters: $|D / h c|=0.3120$ $\mathrm{cm}^{-1}$ and $E / h c \mid=0.0518 \mathrm{~cm}^{-1}$.

\section{Results and Discussion}

The photochemical reaction of p-substitued 2-diazo- propiophenone (DPP) in acetonitrile (MeCN) were set up at the initial concentrations of $[\mathrm{DPP}]=1.0 \times 10^{-3} \mathrm{~mol} / \mathrm{l}$. and $[\mathrm{MeCN}]=3.00 \times 10^{-1} \mathrm{~mol} / 1$. The reaction was followed until the concentration of DPP was decreased to $1 \times 10^{-5}$ $\mathrm{mol} / \mathrm{L}$, and then the concentration of MeCN showed to be decreased by $2.970 \times 10^{-1} \mathrm{~mol} / \mathrm{L}$. The MeCN components of a secondorder reaction remains effectively constant through out the kinetic runs.

During the reaction occurs, DPP concentration revealed a change of a factor showing 100 , and the MeCN concentration changed only a factor showing 1,01 .

The observed rate constants are obtained by the following equation (1) ${ }^{20}$

$$
\ln \frac{\left(A_{\infty}-A_{0}\right)}{\left(A_{\infty}-A_{l}\right)}=k_{t, h}, \mathrm{t}+\text { constant }
$$

where $A_{\omega}$ is the measurement of optical density at $248 \mathrm{~nm}$ (for $p-\mathrm{OCH}_{3}$ ) and at the time, $A_{\infty}$ on the spectrum, and $A_{f}$ and $A_{0}$ are the measurements of optical density at the time, $t$

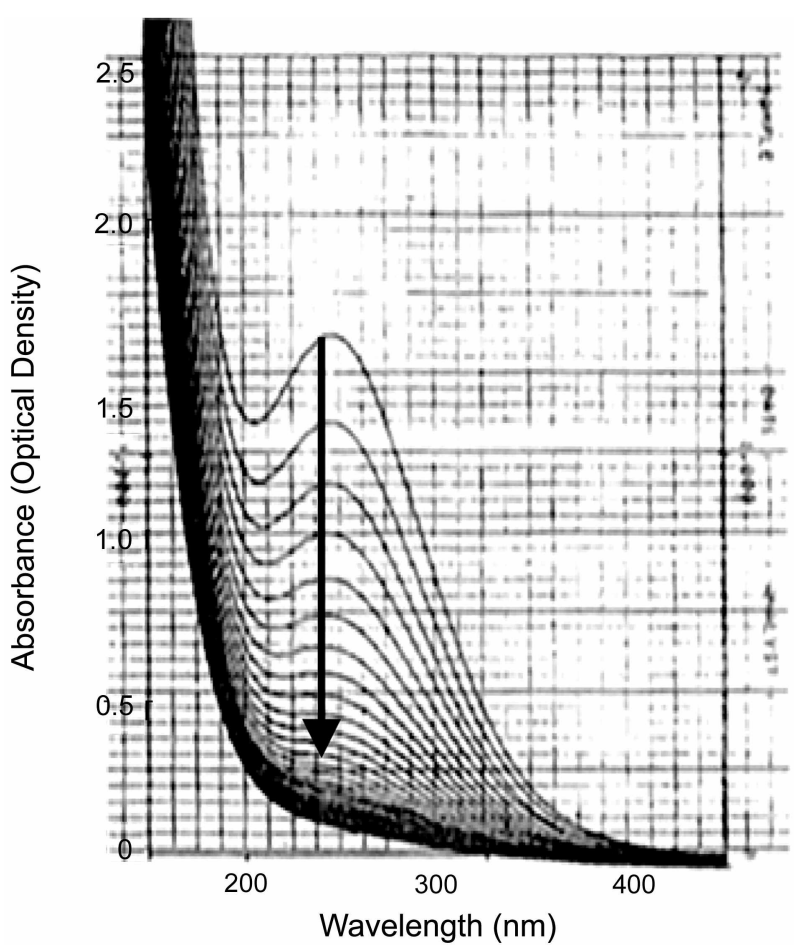

rigure I. 'l'he absorption spectra of $p$-methoxy-2-diaropropiophenone in $\mathrm{MeCN}$ as a function of reaction time in dicthyl ether solution at $313 \mathrm{~K}\left(\lambda_{\max }: 248 \mathrm{~nm}\right)$.

Table 1. Pscudo First-Order Rate Constants $\left(k_{o b i} \times 10^{+} \mathrm{sec}^{-1}\right)^{a}$ for the Photochemical Decomposition of $p$-Substituted 2-Diazopropiophenone in $\mathrm{MeCN}$ at 313.323 and $333 \mathrm{~K}$

\begin{tabular}{|c|c|c|c|c|c|c|c|}
\hline $\begin{array}{c}\text { Temp. }(K)^{\prime} \\
(X=)\end{array}$ & 313 & 323 & 333 & $\begin{array}{c}E a \\
(\mathrm{kcal} / \mathrm{mol})\end{array}$ & $\begin{array}{c}\Delta I f \\
\text { (kcalimol) }\end{array}$ & $\begin{array}{l}\Delta 5: \\
(c, u .)\end{array}$ & $\begin{array}{c}\Delta \sigma^{*} \\
\text { (kcalimol) }\end{array}$ \\
\hline$p-\mathrm{OCH}_{3}$ & 148 & 176 & 204 & 3.32 & 2.68 & -58.4 & 21.5 \\
\hline$p-\mathrm{CH}_{i}$ & 14.3 & 17.8 & 21.2 & 4.08 & 3.44 & -60.6 & 23.0 \\
\hline$p-\mathrm{H}$ & 9.11 & 12.9 & 16.7 & 6.28 & 5.64 & -54.4 & 23.2 \\
\hline$p-\mathrm{F}$ & 3.50 & 6.13 & 8.75 & 9.50 & 8.86 & -46.0 & 23.7 \\
\hline
\end{tabular}

"Observed rate constants correspond to the average of two independent runs; typical standard deviation is $\pm 3 \%$. ${ }^{2} \mathrm{Temp} .(\mathrm{K})=(313 \pm 0.0 \mathrm{l}) \mathrm{K}$. (323. $0.01) \mathrm{K}$ and $(333=0.03) \mathrm{K}$ 


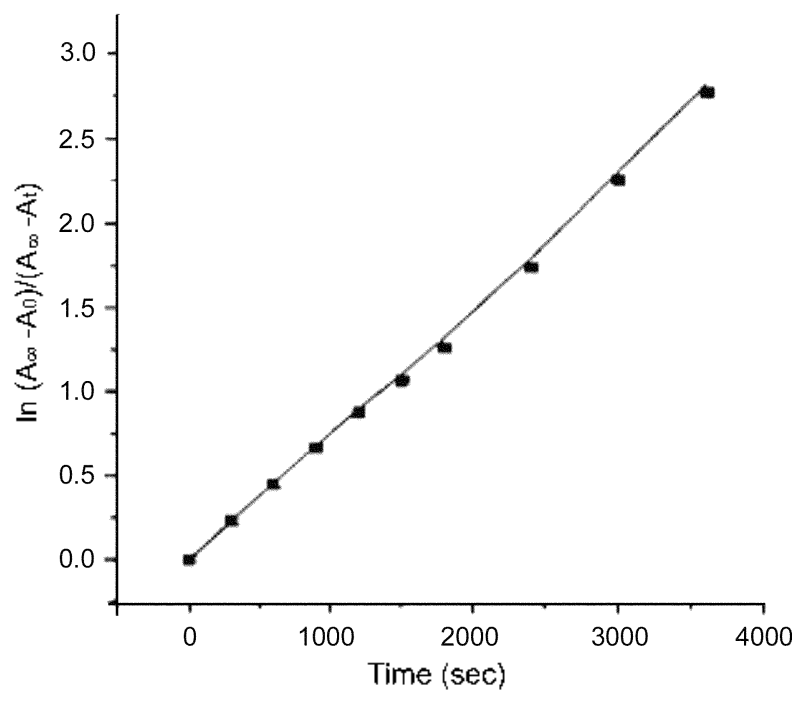

Figure 2. Plot of $\left.\ln \left(\Lambda_{\omega}-\Lambda_{1}\right)\right)\left(\Lambda_{\omega}-\Lambda_{t}\right)$ vs time for the photolytic reaction of $p$-nncthoxy-2-diazopropiophenonc in MeC N at $313 \mathrm{~K}$ $\left(\lambda_{\text {mix }}: 248 \mathrm{~nm}\right)$.

and to at the same wavelength. A typical kinetic run using UV/Vis spectrophotometer was shown in Figure 1.

Under the condition given in Tablel, the first-order rate constant of the photochemical reaction of $p$-methoxy-2diazopropiophenone (DPP) in MeCN was calculated as 148 $\times 10^{-1} \mathrm{sec}^{-1}$ from the data in Figure 2 . The observed rate constants, $k_{\text {obs }}$ are summarized in Table 1 , where the activation energy $\left(E_{\mathrm{a}}\right)$, activation enthalpy $\left(\Delta H^{*}\right)$ and activation Gibbs free energy $\left(\Delta C^{\circ}\right)$ are also shown.

Generally, the activation enthalpy for decomposition reaction of aryl diazo compounds is known as 3-4 kcal/mol ${ }^{1.7}$ and the activation energy of the essentially diffusioncontrolled reaction is $2-3 \mathrm{kcal} / \mathrm{mol}^{13}$ The latter value is only an apparent activation energy which results from the decrease in $k_{\text {ditt }}$ at low temperature due to increased solvent viscosity,

The activation enthalpy and the activation energy show
$2.68-8.86 \mathrm{kcal} / \mathrm{mol}$ and $3.32-9.50 \mathrm{kcal} / \mathrm{mol}$, respectively in Table 1 . There is a wide difference in $E_{a}$ and $\Delta H^{*}$ between DPP with the electron donating substituents and DPP with the electron withdrawing substituents. Decomposition reactions of DPP with the electron donating substituents are consistent with the diffusion controlled reaction, but those of DPP with the electron withdrawing substituents are in striking contrast to the diffusion-controlled reaction mechanism. If the reactions of DPP with the electron withdrawing substituents do not proceed through the diffusion-controlled reaction, it would expect to produce the arine product (10) before DPP reacts with MeCN as shown in Scheme 7.

It has been reported that the irradiation of typical carbene precursors using lamp or laser such as diphenyl diazomethane or tetraphenyloxirane, can lead to different products and product distributions. ${ }^{1 \cdot 4}$ However, the irradiation of DPP with MeCN does not give a azine product (10). This seems that the neighboring methyl group in DPP furnishes a steric hinderance at the step of azine formation. If acetonitrile ylide would be produced, then the product of DPP reaction gives an ylide intermediate (11) as shown in Scheme 8.

The reaction was identified for the final product, to find out a possibility to produce azine carefully. However the final product gives only 1-methyl-3-p-substituted phenyloxirene (MPO) and the acetontrile ylide was not found in this reaction.

Griller.3 has reported that the azine product comes from the photochemical reaction of diphenyldiazomethane in $\mathrm{MeOH}$. And it shows high activation energy like $5-7 \mathrm{kcal} /$ mol. The result also shows a different tendency that is: the carbene-carbene coupling reaction is in accord with the diffusion-controlled reaction as much as a neglect of the activation energy value.

In this study, it shows low activation energy for the electron donating group and high activation energy for electron withdrawing group as shown in Table 1 . This result means that the reaction is involved in a different mechanism which is proceeded by $\mathrm{MeOH}$ which has been reported by<smiles>[X]c1ccc(C(=O)C(C)=[W])cc1</smiles><smiles>[X]c1ccc(C(=O)/C(C)=N/N=C(\C)C(=O)c2ccc([X])cc2)cc1</smiles>

Scheme 7<smiles>[X]c1ccc(C(=O)C(C)=[W])cc1</smiles><smiles>[X]c1ccc(C(=O)CC)cc1</smiles><smiles>CC(C)(C)C(C)(C)N</smiles><smiles>[X]c1ccc(C(=O)C(C)[N+]#CC)cc1</smiles>

Scheme 8 
<smiles>[X]c1ccc(C(=O)C(C)=[V])cc1</smiles>

12

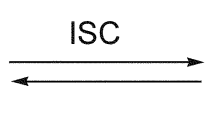<smiles>[X]c1ccc(C(=O)C(=C)C)cc1</smiles>

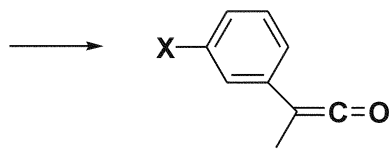

Scheme 9

Griller.

Many studies ${ }^{20.30}$ reported that carbenes usually produce acetone and nitrile ylides in the case of carbene reaction in acetone or acetonitrile. Therefore it is necessary to examine a possibility for carbene ylide intermediate spectrophotometrically.

In this reaction we checked the possibility of carbene ylide intermediate using UV/vis spectrophotometer. The result did not show the evidence for acetonitrile ylide intermediate.

The reaction of DPP ( $p$-substituted phenyl- $\alpha$-diazoketone: $\mathrm{PDK}$ ) in MeCN is achieved in low the activation enthalpy and activation energy as shown in Table 1. This is believed to be an existence of singlet phenylketocarbene (12, S-PKC) as shown in Scheme 9. The singlet carbene (12) should be produced from the photodecomposition of DPP. Generally, it is well known that ylide intermediate is produced from the triplet phenylketocarbene $(1, T-P K C),{ }^{1-3} \mathrm{lt}$ is estimated that the singlet carbene changes to the triplet carbene after intersystem crossing quickly as shown in Scheme 9.

In order to confirm the spin state of the carbene, $\mathrm{DPP}(p-\mathrm{H})$ was photolyzed in cryogenics at $77 \mathrm{~K}$. The observed $Г \mathrm{PR}$ spectrum is assigned to triplet carbene which has either a ground triplet state or a triplet state within a few $\mathrm{kcal} \cdot \mathrm{mol}^{-1}$ of the ground state as shown $D / h \mathrm{c} \mid=0.3120 \mathrm{~cm}^{-1}$ and $E / h c \mid=0.0518 \mathrm{~cm}^{-1}$. The value of $E / D=0.166(=0.0518$ i 0.3120 ) is consistent with the values of typical triplet ketocarbenes. ${ }^{6}$ The value of $E / D$ for ketocarbene produced DPP is similar to those of $E / D$ of other ketocarbene, for example, as formyl carbene $(\mathrm{H}-\mathrm{CO}-\ddot{\mathrm{C}}-\mathrm{H})$ and $\left(\mathrm{CF}_{3} \mathrm{CO}^{\mathrm{C}}-\mathrm{CF}_{3}\right)$ perfluoroacetylmethylcarbene as shown as 0.142 and 0.165 . however it is a little bit lower than the value of 0.290 for benzoylphenylcarbene $\left(\mathrm{C}_{6} \mathrm{H}_{5} \mathrm{CO}-\ddot{\mathrm{C}}-\mathrm{C}_{6} \mathrm{H}_{5}\right)$.

Photolysis $(\lambda=340 \mathrm{~nm} \pm 3 \mathrm{~nm}$ ) of benzoylphenylcarbene, $\left(\mathrm{C}_{6} \mathrm{H}_{5} \mathrm{CO}-\ddot{\mathrm{C}}-\mathrm{C}_{6} \mathrm{H}_{5}\right)$ gives a triplet EPR signals in the corresponding to diazo precursor compound as powder matrix at $77 \mathrm{~K}$ as shown as $\mid D / h c=0.3123 \mathrm{~cm}^{-1}$ and $\mid E / h c=0.0519$ $\mathrm{cm}^{-1}$. Upon analysis of the two results of the triplet intermediate at low temperature. $77 \mathrm{~K}$ and the singlet intermediate at $313 \mathrm{~K} \cdots 333 \mathrm{~K}$, it is estimated that the two intermediates exist at the early step just after production of the reaction of DPI? The values for benzoylphenylcarbene are close to the value of the ketocarbene, 12 and the result for benzoylphenylcarbene strongly rationalizes that the keto triplet carbene is produced exactly from the photolysis of DPP. It supports the evidence that exists of an intersystem crossing (ISC) to the singlet carbene as shown in Scheme 9.

[n this research the reaction series, the rate constants are observed at the step of the transition state because the disappearance of the maximum wavelength $\left(\lambda_{\max }=253 \mathrm{~nm}\right)$ for $p-\mathrm{H}$ is in accord with the formation of the final product

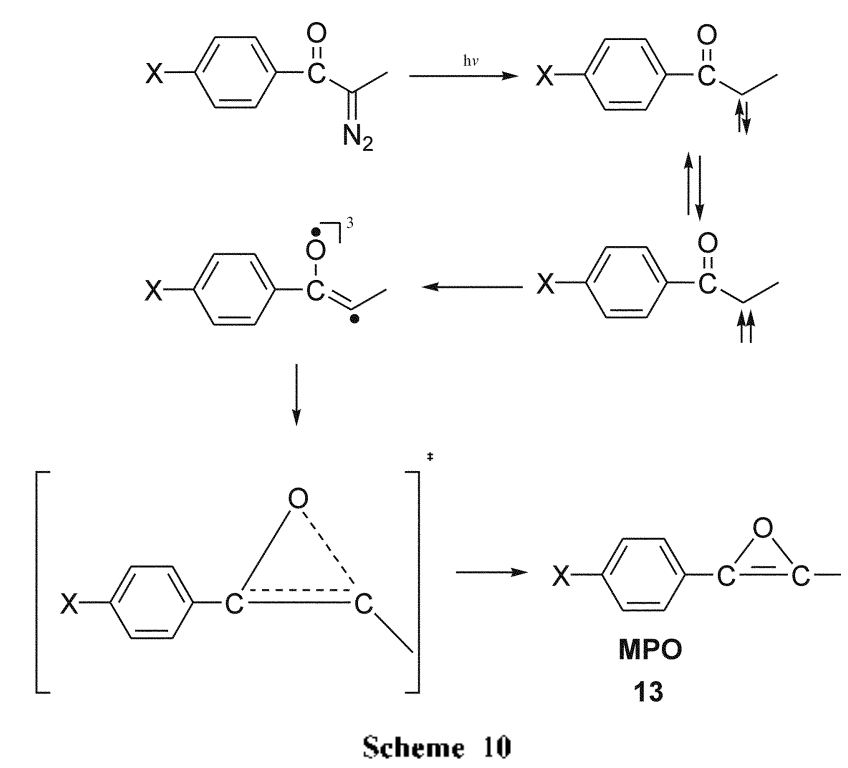

(MP0, 13) as shown in Scheme 10.

The product MPO could result to be produced by intramolecular reaction of triplet radicals as shown in Scheme 10.

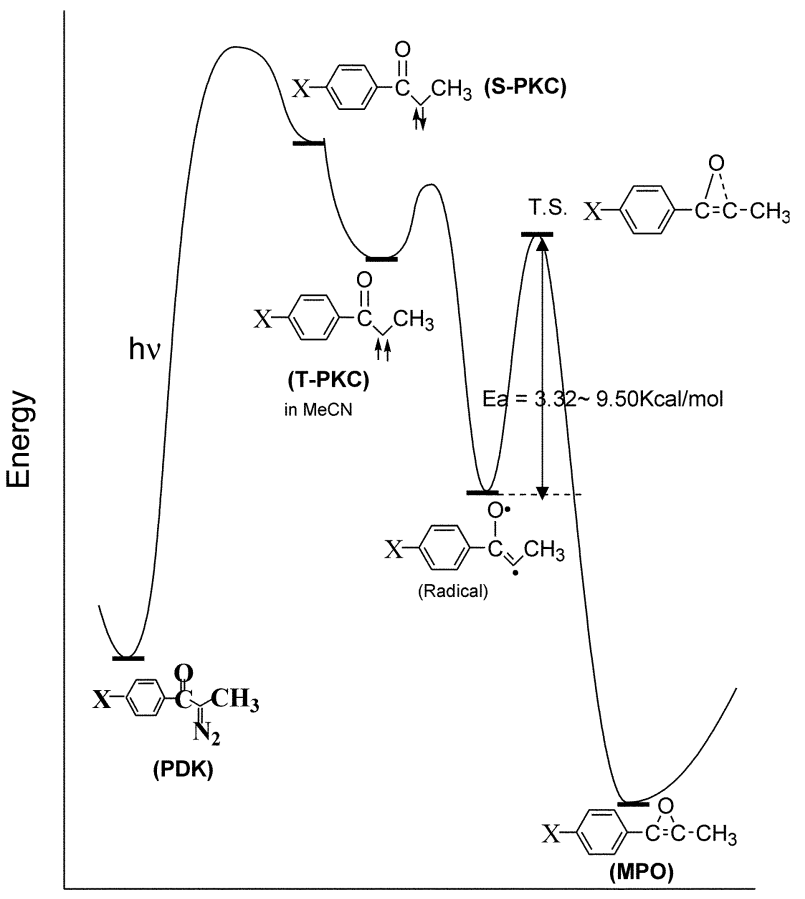

Reaction Coordinates

Figure 3. Proposed energy surface for the photochemical decomposition reaction of $p$-substituted 2-diazopropiophenone in $\mathrm{MeC}$. 


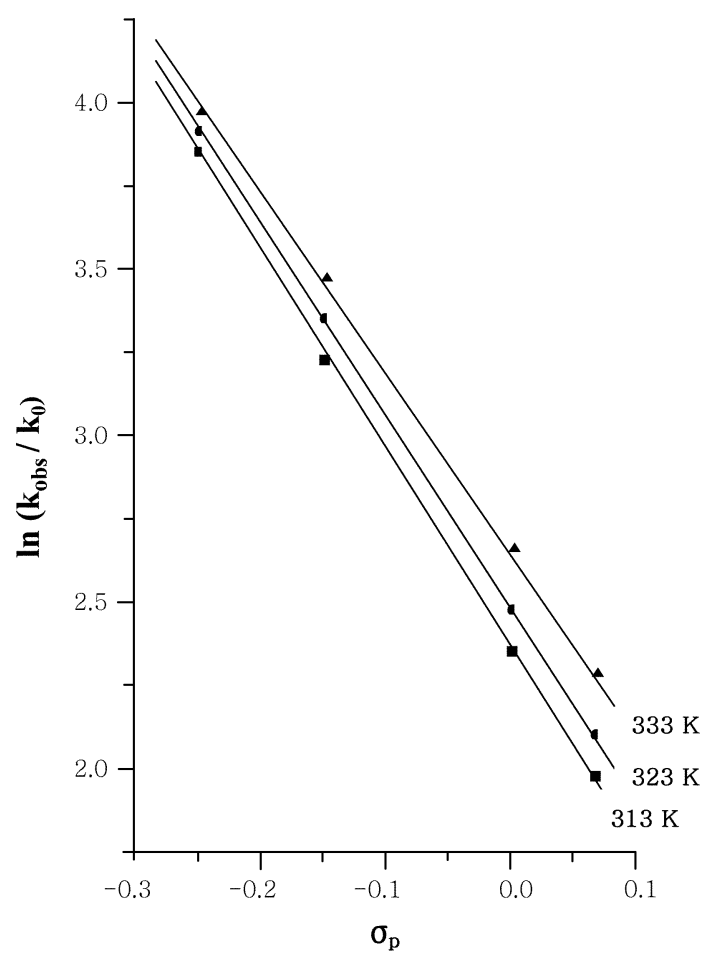

Figure 4. Hammetl plots lor the photochemical decomposition reaction of $p$-subslituled 2-diazopropiophenone in MeC $\mathrm{N}$.

Pople and co-workers ${ }^{15}$ have calculated the potential energy surface for reaction of methylene with ammonia. The result for the reaction shows that the potential energy gap between the ylide internediate and the transition state is 13 $\mathrm{kcal} / \mathrm{mol}$ and the energy gap between the transition and the final product is $85 \mathrm{kcal} / \mathrm{mol}$. In the reactions of DPP with $\mathrm{MeCN}$ the activation energies show in the range of 3.32-9.50 $\mathrm{kcal} / \mathrm{mol}$, it indicates a comparatively low value with other carbene reaction, ${ }^{1 \cdot 1}$ If the triplet radical would be generated as shown in Scheme 10 at the first step, the energy level of the radical should be higher than the energy level of MPO. And a transition state corresponding to $\mathrm{C} \cdots \mathrm{O}$ bond formation step exists between the radical and MPO. It could be illustrated as shown in Figure 3. The fact that the activation energy which shows a wide range of $3.32-9.50$, it infers a conclusion that the transition state is affected strongly by the substituent. For examination of the substituent effect. the logarithıns of rate constants were plotted against the substituent constants as shown in the Hammett plot of Figure 4 . The high negative $\rho$-values show ranging $5.95-6.12$.

It indicates that the reaction of $\mathrm{DPP}$ in $\mathrm{MeCN}$ is affected largely according to the substituents. That is, in the case of electron donating substituents substituted at the paraposition of phenyl ring, the electrons in oxygen atom of the $\mathrm{C}-\mathrm{O}$. radical would be moving into the right-hand carbon atom of $\mathrm{C}=\mathrm{C}$ bond and then, it becomes a state of developed bond formation. However, in the case of electron-withdrawing substituents, it presents that the electrons on $\mathrm{C}-\mathrm{O}$ - radical is barely moved into the right-hand carbon atom of $\mathrm{C}=\mathrm{C}$

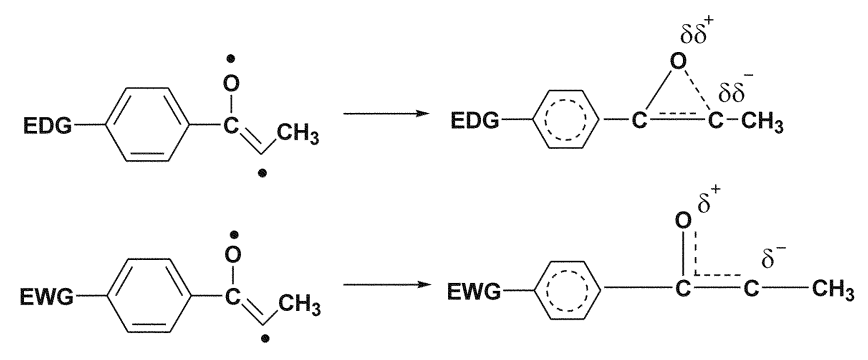

EDG (Electron Donating Group)

EWG (Electron Withdrawing Group)

\section{Scheme 11}

bond that is a striking contrast to the electronic state of electron-donating substituents.

It is proposed that the transition state corresponds to an appropriate step to make triangle ring in view of the activation parameters (low activation energy and low enthalpy compared with other carbene reactions). A high negative value of $\rho$ indicates that a positive charge develops at the reaction center, the oxygen atom of carbonyl group in DPP as shown in Scheme 11 .

In conclusion, it is shown that the photochemical reactions of $p$-substituted 2-diatzopropiophenones (DPP) give the products corresponding to 1 -methyl-3-p-substituted phenyloxirene (MPO). The reactions are achived in low activation energy and low activation enthalpy. The kinetic data and Г.PR spectrum are in accord with a phenomenon that occurs in interconversion between singlet carbene and triplet carbene.

Acknowledgment. We are grateful to Dong-A University for financial support. We thank the Korea Basic Science Institute for assistance in obtaining T.PR spectra.

\section{References}

1. Trorfolo. A. M.: (jibbons. W. A. J. Am. Chem. Soc. 1966. 88.172.

2. Moritani. I.: Murahashi. S.-I.: Vishino. M.: Kimura. K.: Tsubomura. H. Tetrathe dron Leth. 1966. 4. 373.

3. Graham. D. J.: Wang. C. L. J. Chem. Phws. 1986. 85. 4441.

4. Fujiwaria Y: Sasaki, M.: Tanimoto, Y.: Ito, M. J. Phys: Chem. 1989. 93.702

5. Scaidno. J. C.: Weir D. Can. J. Chem. 1988. 66. 491.

6. Sander. W. Angew (hem. 1986. 98. 255: Angew (Wem. Int Ed. Eingl. 1986. 25.255

7. Sander. W.: Bucher. G.: Wierlacher. S. Chem. Rev. 1993. 1583.

8. Murai. II.: Torres. M.: Strausz. O. P. J. Am. Chem. Soc. 1980. $/ 02$. 5104.

9. Troyolo. A. M. Ace (hem. Res. 1968. /, 329.

10. Murai. H.: Safärik. I.: Torres. M.: Strause. O. P.J. Am. Chen. Soc. 1988. 110.1025.

11. Moss. R. A.: Zdrojewski. T. J. Phys. Org. Chem. 1990. 3. 694

12. Moss, R. A.: Chang, .1. J. Tetrohedron Leit. 1981, 22. 3749.

13. Jackson. J. J:.: Soundararajan. N.: Platz. . M. S.: Liu. M. T. I I. J. tm. (hem. Soc 1988. II0.5595.

14. Gould. L. R.: lurro. V. I: Butcher. J.. Jr.: Doubleday. C.. Jr:: Hacker. N. P.: Lehr. G. F.: Moss. R. A.: Cos. D. P.: Guo. W.: Munjal. R. C.: Perez. L. A.: Fedornnski. M. Tetrahedrun 1985. 4/. 
1587.

15. Turro. N. J.: Cha. Y:: Gould. I. R.: Padwa. A.: Gasdaska. J. R.: Tomas. M. J. Org. Chem. 1985, 50.4417.

16. Padwa. A.: Rosenthal, R. I.: Dent W: Filho, P.: Turro. N. J.: Hrovat D. A. Gould I. R. J. Org Chen 1984. 49.3174.

17. Doering. W. E.: Buttery. R. G.: Laughlin. R. G.: Chaudhuri. N. $J$. Am. Chem. Soc. 1956.78.3224.

18. Tomioka. H.: Okuno. H.: Izawa. Y. J. Chem. Soc. Perhin Trans. 2 1980,1636

19. Tomioka, H.: Okuno. H.: Izawa. Y. J. Org Chem. 1980. $45,5278$.

20. Moss R. A. Lill. W: Ge C. S. J. Phts Org. Chemt 1993. 6. 376.

21. Moss. R. A.: Kmiecik-Lawrynowicz. G.: Krogh-Jespersen. K. $J$. Org. Chem. Soc. 1992.114.959.
22. Moss. R. A.: Ho. G.: Liu. W. J. Am. Chem. Soc. 1992. 114. 959

23. Schaefer. H. F. III. Acc. Chem. Res. 1979. 12. 288.

24. Moss. R. A.: Chang, M. J. Tetrohedron Lett. 1981. 22, 288.

25. Moore. J. A.: Reed. D. E. Org. Simth. Coll Vol. I'1973. 351.

26. Sung. D. D. Kang. D. Y. Ryu, Z. H. Bull. Korean Chent. Soc. 1997. $18(9) .945$

27. Sung. D. D.: Choi. M. J.: Ha. K. M.: Uhm. T. S. Bull. Korean Chem. Soc. 1999. $20(8) .935$.

28. Sung. D. D.: Lee, J. P.: Lee. Y. H: Ryu. Z. H.: Ryu. W. S. J. Photosei $2000,7(1), 15$.

29. Kinetics and Spectroscopy of Carbenes and Biradicals: Platz. M. S.. Ed.: Plenum Press: New York. 1990: p 258.

30. Hermann. W.: Köcher. C. Angew: Chem. Iht Ed. Engl. 1997. 36. 2177. 